\title{
The Contribution of Long-Terms Static Interactions Between Minerals and Flotation Reagents for the Separation of Fluorite and Calcite
}

\author{
Leiming Huang ${ }^{1}$, Qiang Zeng ${ }^{1}$, Liang $\mathrm{Hu}^{1}$, Yuehua $\mathrm{Hu}^{1}{ }^{1}$, Hui Zhong ${ }^{2, *}$ and Zhiguo $\mathrm{He}^{1, *}$ \\ 1 School of Minerals Processing and Bioengineering, Central South University, Changsha 410083, China; \\ hlm@csu.edu.cn (L.H.); syzndx@163.com (Q.Z.); huliang2018@csu.edu.cn (L.H.); hyh@csu.edu.cn (Y.H.) \\ 2 School of Life Sciences, Central South University, Changsha 410083, China \\ * Correspondence: hmmzhjj@csu.edu.cn (H.Z.); zghe@csu.edu.cn (Z.H.); Tel.: +86-189-7310-9476 (H.Z.); \\ +86-133-1958-2715 (Z.H.)
}

Received: 9 October 2019; Accepted: 10 November 2019; Published: 12 November 2019

\begin{abstract}
The influences of long-term static interaction between flotation reagents and minerals on mineral surface properties and their flotation behaviors were investigated in this work. Single mineral results showed that when the static interaction time between flotation reagents and minerals increased from 0 to 8 days, there were no significant differences in the recovery of fluorite (ranging from $77.50 \%$ to $74.50 \%$ ), while the recovery of calcite dramatically decreased from $97.17 \%$ to $41.13 \%$. The collector adsorption results indicated that after the long-term static interaction between the collector and minerals, adsorption and desorption of collector on the minerals occurred, and the adsorption amount of collector on fluorite and calcite varied from $0.396 \mathrm{mg} / \mathrm{g}$ to $0.421 \mathrm{mg} / \mathrm{g}$, and from $0.444 \mathrm{mg} / \mathrm{g}$ to $0.404 \mathrm{mg} / \mathrm{g}$, respectively. The contact angles of fluorite and calcite decreased from $134.3^{\circ}$ and $105.0^{\circ}$ for 0 days to $109.7^{\circ}$ and $52.5^{\circ}$ for 8 days, respectively, which demonstrated that the fluorite had a higher hydrophobicity than that of calcite after 8 days of static interaction between the minerals and collector. The Fourier transform infrared spectroscopy (FTIR) analysis showed that there were chemisorptions between the collector and the surfaces of the fluorite and calcite. Meanwhile, the X-ray photoelectron spectroscopy (XPS) results further elucidated that the amount of $\mathrm{C}=\mathrm{O}$ from the oleic acid $(\mathrm{OA})$ molecule for calcite treated for 8 days was less than for that treated for 0 days. In addition, the flotation results of the tailings from Jiangxi containing fluorite and calcite, indicated that the grade and recovery of fluorite increased from $87.18 \%$ and $40.99 \%$ for 0 days to $93.00 \%$ and $46.01 \%$ for 8 days, respectively, indicating that the separation of fluorite from calcite could be achieved via increasing the long-term static interaction between the flotation reagents and minerals.
\end{abstract}

Keywords: fluorite; calcite; flotation; static interaction; chemisorption

\section{Introduction}

Fluorite $\left(\mathrm{CaF}_{2}\right)$, the most important fluorine-containing mineral and the major source of fluorine in the industry, has been considered to be a valuable strategic resource [1,2]. It has been widely used in the manufacture of glass, steelmaking, the production of hydrofluoric acid, pottery, enamel, drugs and catalyst [3-5].

Fluorite is generally associated with calcite $\left(\mathrm{CaCO}_{3}\right)$ in deposit, and $30 \%$ of fluorite and $10-20 \%$ or less of calcite are usually contained in the fluorite-rich ore [6]. To meet the market's demand, before entering the fluorite commercial market, the grade of most fluorite minerals has to be improved by flotation, which is a method of utilizing the physicochemical properties of mineral surfaces [7]. However, the effective separation of fluorite from calcite has always been a worldwide difficult problem 
due to the similar surface physicochemical properties between fluorite and calcite, such as the solubility and the $\mathrm{Ca}^{2+}$ active sites [6,8,9]. Therefore, the development of novel flotation methods is urgently needed to solve the effective separation of these two minerals.

Recently, many studies have been conducted on this aspect. Different mechanisms of fatty acid collector adsorption on the mineral surface, including physisorption, chemisorption, surface precipitation and the formation of hydrophobic aggregates, have been reported in previous studies [1015]. For instance, Ren et al. [16] reported that valonea extract exhibited a strong inhibitory effect on calcite by hindering the chemical reaction of oleate species with $\mathrm{Ca}^{2+}$ surface sites, which facilitated the selective separation of fluorite and calcite. Gao et al. [6] found that the calcite could be efficiently recovered from fluorite by using citric acid, sodium fluoride and sulfoleic acid as a depressant, adjuster and collector, respectively. Fuerstenau et al. [17] studied the complex behavior of fatty acids in fluorite flotation, and proved that the boundary of the formation zone of palmitic acid and calcium palmitate had an effect on the flotation and wetting behavior of fluorite. Helbig et al. [18,19] found that the flotability of fluorite could be significantly improved when the anionic collector sodium $\mathrm{N}$-dodecanoyl sarcosine was used in combination with the cationic collector dodecylammonium chloride as a co-collector, compared with the anionic collector alone. Meanwhile, some new effective depressants, such as sodium polyacrylate and tannic acid, were developed to enhance the selective recovery of fluorite $[9,20]$. However, to the best of our knowledge, the effect of the static interaction time between flotation reagents and minerals on the flotation behaviors of minerals is often neglected. Traditionally [21], it is generally believed that the adsorption process of flotation reagents on minerals' surfaces can achieve equilibrium and remain stable within minutes or within tens of minutes, while the long-term static interaction between collectors and minerals has not been reported yet. Moreover, it is well known that there is a large amount of flotation reagents adsorbed onto the surface of flotation tailings, which would in turn cause environmental pollutions [22], and their long-term static accumulation behaviors on tailings are still unclear. Therefore, studying the long-term static interaction between flotation reagents and minerals' surfaces will also be very important in developing an environment-friendly way to stack flotation tailings.

In this work, the flotation behaviors of fluorite, calcite and flotation tailings were studied based on the static interaction between minerals and flotation reagents under different interaction times. Collector adsorption, zeta potential, contact angle, Fourier transform infrared spectroscopy (FTIR) and X-ray photoelectron spectroscopy (XPS) of a single mineral were further employed to unravel the mechanisms involved in the flotation behaviors of these two minerals.

\section{Materials and Methods}

\subsection{Materials and Reagents}

All hand-picked fluorite and calcite samples were derived from Chenzhou, Hunan province in China. These samples were crushed to $-3 \mathrm{~mm}$ and subsequently ground to $-74+38 \mu \mathrm{m}$ in a ball mill of corundum (Shanghai Gongtao Ceramics Co., Ltd, Shanghai, China) for micro-flotation tests. The purities of the mineral samples were above $99 \%$ according to the X-ray diffraction (XRD) spectra (Figure 1). The XRD equipment is TTR III (Rigaku, Tokyo, Japan) and patterned in the range of $5^{\circ}-80^{\circ}$, consisting of $0.02^{\circ}$ with a $2 \mathrm{~s}$ counting time at $40 \mathrm{kV}$ and a tube current of $30 \mathrm{~mA}$.

Oleic acid (OA) and kerosene were purchased from Tianjin Kemiou Chemical Reagent Co., Ltd. (Tianjin, China) and Tianjin Hengxing Chemical Reagent Co., Ltd. (Tianjin, China), respectively. A water glass was used as a depressant. Hydrochloric acid $(\mathrm{HCl})$ and sodium carbonate $\left(\mathrm{Na}_{2} \mathrm{CO}_{3}\right)$, obtained from Sinopharm Chemical Reagent Co., Ltd. (Shanghai, China), were used to adjust the solution $\mathrm{pH}$ value. All the chemical reagents that were used were analytically pure without further purification. Deionized water was used in this study, and all of the experiments were repeated three times. 


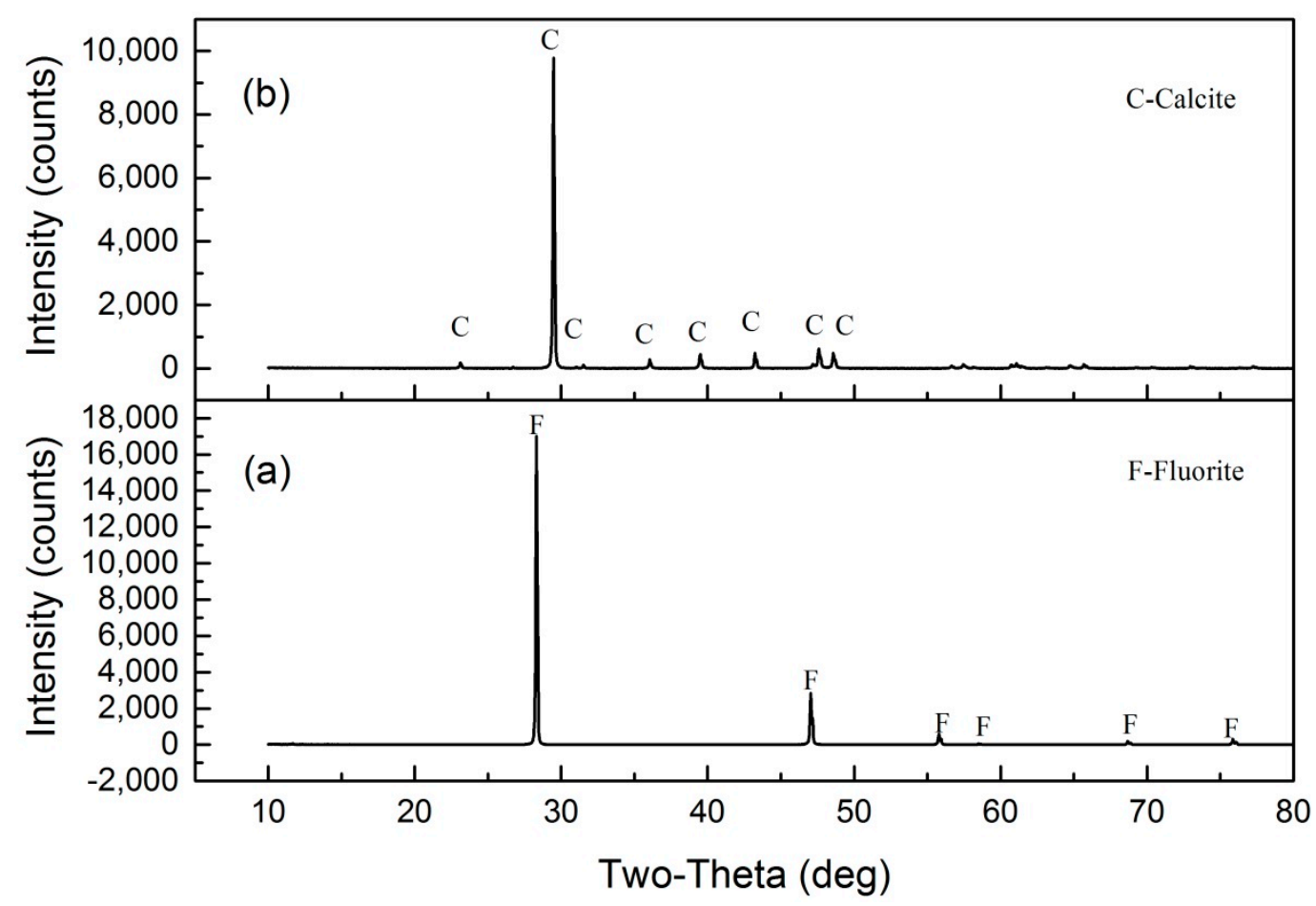

Figure 1. The X-ray diffraction (XRD) spectra of the (a) fluorite and (b) calcite samples.

\subsection{Micro-Flotation Tests of Single Mineral}

Micro-flotation tests of a single mineral were carried out on a micro flotation machine (XFGC, Jilin Exploration Machinery Plant, Changchun, China) with a 40-mL hitch groove flotation cell at a speed of $1992 \mathrm{rpm}$. The flotation pulp of the single mineral was prepared by adding $2 \mathrm{~g}$ of the single mineral sample to $35 \mathrm{~mL}$ deionized water, before stirring for $2 \mathrm{~min}$. After adjusting the $\mathrm{pH}$ value by $\mathrm{HCl}$ or $\mathrm{Na}_{2} \mathrm{CO}_{3}$ (stirring time of $3 \mathrm{~min}$ ), the depressant of the water glass and collector of the mixture of $\mathrm{OA}$ and kerosene with a volume ratio of 1:1 were added into the flotation cell. Additionally, the corresponding stirring times were $2 \mathrm{~min}$ and $5 \mathrm{~min}$, respectively. Subsequently, the flotation of the single mineral was performed for $6 \mathrm{~min}$, and the obtained concentrate and tailings were filtered, dried and weighted to calculate the recovery rate, respectively. What requires special attention is that the above experiments results were marked as 0 days, i.e., $18 \mathrm{~min}$, of static interaction, which referred to a state without agitation under natural conditions. Targeting the flotation of the mixture under different static interaction times, the mixture that included the minerals and flotation reagents was brought to flotation after having preset the long-term static interaction time. The flotation time was also $6 \mathrm{~min}$, and the preset static interaction time varied from 2 to 8 days. In this work, all tests were carried out at $\mathrm{pH} 10$, and the concentration of the depressant and collector was $1200 \mathrm{~g} / \mathrm{t}$.

\subsection{Collector Adsorption Measurements}

The single mineral samples $(2 \mathrm{~g})$ were placed in a $50 \mathrm{~mL}$ conical flask with $35 \mathrm{~mL}$ deionized water. After adjusting the $\mathrm{pH}$ value to 10 , the mixture was stirred via the flotation machine, and the addition reagents and order were the same as for the flotation tests. Subsequently, the supernatant samples were obtained by centrifugation for $10 \mathrm{~min}$ at 10,000 rpm, when the long-term static time was 0 or 8 days. Given that the collector used in this study was the mixture of OA and kerosene, the concentration of the collector in the supernatant was replaced by the mass of total organic carbon (TOC), which was measured by a total organic carbon analyzer (TOC-L, Shimadzu, Japan). 
The adsorption capacities of the minerals under different static interaction times were calculated according to the following Equation (1) [14]:

$$
\Gamma=\frac{\left(C_{0}-C_{t}\right) \mathrm{V}}{m},
$$

where $\Gamma$ represents the adsorption capacities of minerals to collector $(\mathrm{mg} / \mathrm{g}), \mathrm{C}_{0}$ is the initial concentration of the collector in solution before adding the minerals $(\mathrm{mg} / \mathrm{L}), \mathrm{C}_{\mathrm{t}}$ is the collector concentration of the supernatant after a long-term static interaction time $(\mathrm{mg} / \mathrm{L}), \mathrm{V}$ is the mixture volume $(\mathrm{L})$ and $\mathrm{m}$ is the mass of mineral samples (g).

\subsection{Zeta Potential Measurements}

The zeta potentials of the fluorite and calcite samples treated with the same reagents for 0 and 8 days were measured at room temperature using a zeta potential analyzer (Malvern Zetasizer Nano ZS, Malvern Instruments Ltd. Shanghai, China). $20 \mathrm{mg}$ samples were put into a $100 \mathrm{~mL}$ beaker with $40 \mathrm{~mL}$ $\mathrm{KCl}$ solution $(0.01 \mathrm{~mol} / \mathrm{L})$ used as a background electrolyte. Following this, the solution was stirred by a magnetic stirrer for $10 \mathrm{~min}$, and the $\mathrm{pH}$ values of the suspension were adjusted to the desired value. After the agitated slurry was left standing for $5 \mathrm{~min}$, the supernatant was used to conduct zeta potential measurements and was measured three successive times.

\subsection{Contact Angle Measurements}

The contact angles of the single mineral samples were tested as follows. The samples were filled into a die with a $35 \mathrm{~mm}$ diameter and then compressed by a compressing kit for $3 \mathrm{~min}$ under a pressure of $20 \mathrm{MPa}$. Subsequently, the disc was slowly and carefully removed from the die [12,23,24]. A liquid droplet was slowly dropped onto the disc, and the contact angles were measured through a video contact angle measuring instrument (JY-82C, Chengde Dingsheng Tester Co., Ltd., Chengde, China).

\subsection{FTIR and XPS Analyses}

The FTIR of the single mineral samples obtained under the different static interaction times of 0 and 8 days were conducted via a Fourier transform infrared spectrometer (Shimadzu, Japan). The samples treated by flotation reagents were mixed and agitated with dried $\mathrm{KBr}$ at a mass ratio of 1:100. Following this, the flaky mixture containing the mineral sample was tested in the range of $4000-400 \mathrm{~cm}^{-1}$.

The XPS spectra of the calcite samples were obtained by using a K-Alpha spectrometer (ESCALAB250Xi, Thermo Fisher-VG Scientific, Waltham, MA, USA) with Al K $\alpha$ radiation ( $15 \mathrm{kV}$ and $6 \mathrm{~mA}$ ) and a pressure of $5 \times 10^{-10} \mathrm{~Pa}$ in the analytical chamber [25]. All binding energies were corrected with reference to the standard C1s peak at $284.8 \mathrm{eV}$. The obtained spectra were fitted and analyzed with the XPS Peak 4.1 software.

\subsection{Flotation Tests of Tailings}

The tailings were obtained from the tin tailings of the Jianfengpo tin-zinc mine in Jiujiang, Jiangxi province, China. Additionally, the main composition of the tailings was presented in Table 1. A feed ore contained $8.55 \%$ fluorite and $4.38 \%$ calcite, and the other main components included quartz $(>60 \%)$, feldspar (around 20\%) and a small amount of skarn minerals. The flotation process used in this work was a one-stage rougher and six-stage cleaner flotation (Figure 2). Furthermore, the grinding fineness $(-74 \mu \mathrm{m})$ of the rougher and cleaner flotation was $85 \%$ and $95 \%$, respectively. The flotation was conducted at $\mathrm{pH} 10$, with a water glass of $1200 \mathrm{~g} / \mathrm{t}$ and a mixture of OA and kerosene of $1200 \mathrm{~g} / \mathrm{t}$.

The flotation tests of the tailings were conducted on a laboratory flotation machine of XFD (Jinlin Exploration Machinery Plant, Changchun, China) at a speed of $1992 \mathrm{rpm}$. The flotation pulp of the tailings was obtained by adding $500 \mathrm{~g}$ samples and $1.0 \mathrm{~L}$ water, followed by stirring for $2 \mathrm{~min}$. 
Subsequently, the $\mathrm{pH}$ adjuster, depressant and collector were added in order. Additionally, the corresponding stirring time was $3 \mathrm{~min}, 2 \mathrm{~min}$ and $5 \mathrm{~min}$, respectively. Finally, the rough concentrate obtained was laid down for 0 and 8 days and further separated by a six-stage cleaner flotation. The final concentrates and tailings were filtered, dried and weighted, respectively. Furthermore, the fluorite and calcite grade of the concentrates and tailings were analyzed to calculate the recovery rate, respectively.

Table 1. The main composition of the tailings.

\begin{tabular}{cccccccccccc}
\hline Composition & $\mathrm{SiO}_{2}$ & $\mathrm{TiO}_{2}$ & $\mathrm{Al}_{2} \mathrm{O}_{3}$ & $\mathrm{FeO}_{\mathbf{x}}$ & $\mathrm{MnO}$ & $\mathrm{CaO}$ & $\mathrm{MgO}$ & $\mathrm{K}_{\mathbf{2}} \mathrm{O}$ & $\mathbf{N a}_{2} \mathrm{O}$ & $\mathbf{P}_{2} \mathrm{O}_{5}$ & $\mathrm{CaF}_{2}$ \\
\hline Content (\%) & 72.22 & 0.10 & 9.25 & 2.62 & 0.03 & 2.45 & 0.20 & 2.30 & 2.20 & 0.08 & 8.55 \\
\hline
\end{tabular}

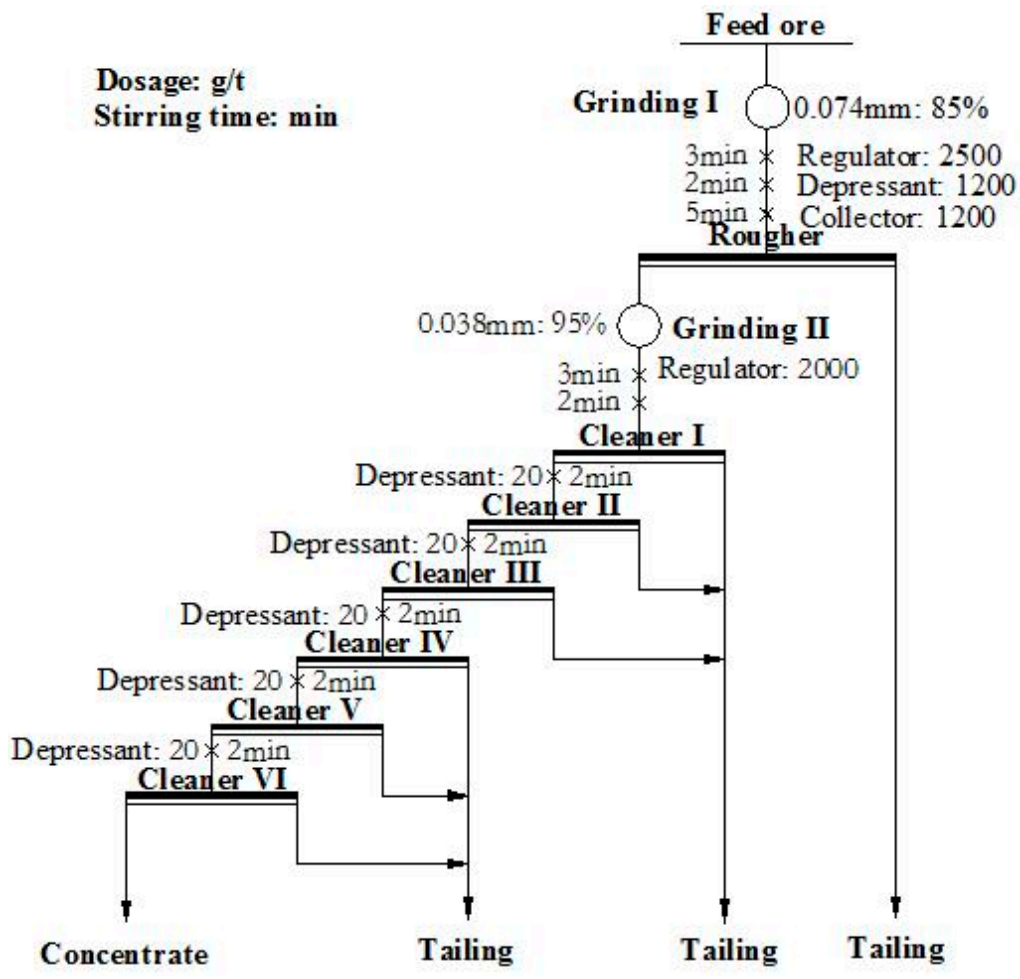

Figure 2. The flow-sheet of the fluorite flotation from the tailing.

\section{Results and Discussion}

\subsection{The Flotation Separation of Fluorite Form Calcite Improved by the Long-Term Static Interaction}

As shown in Figure 3, the total recoveries of fluorite and calcite were $77.50 \%$ and $97.17 \%$, respectively, if there was no static interaction. After 2 days of static interaction, the total recovery of fluorite decreased to $55.33 \%$. When the static interaction time was extended to 8 days, the total recovery of fluorite gradually increased to $74.5 \%$. However, the relations between the total recovery of calcite and static interaction time were completely different from those of the fluorite. It could be seen that the calcite recoveries remained basically stable during 6 days of static interaction and then dramatically decreased to $41.33 \%$ after 8 days of static interaction. Previous studies $[21,26]$ reported that the dissolution process of calcite in water at different $\mathrm{pH}$ ranges could continue for several weeks before reaching equilibrium. However, oleic acid or soluble oleate added in a flotation system would react with calcium ion on the calcite surface to rapidly form calcium oleate, which could then coat the surface of calcite and thereby prevent the further dissolution of calcite. In other words, the decrease in the recovery of calcite that was treated for 8 days should not be mainly caused by the dissolution of calcite. Therefore, the selective flotation separation of fluorite from calcite could be achieved if the flotation reagents interacted with minerals for 8 days. This is an interesting and valuable phenomenon 
which was not reported by the previous literature. Therefore, to understand this reason for the change in the total recovery of fluorite and calcite treated for 0 and 8 days, collector adsorption measurements were carried out.

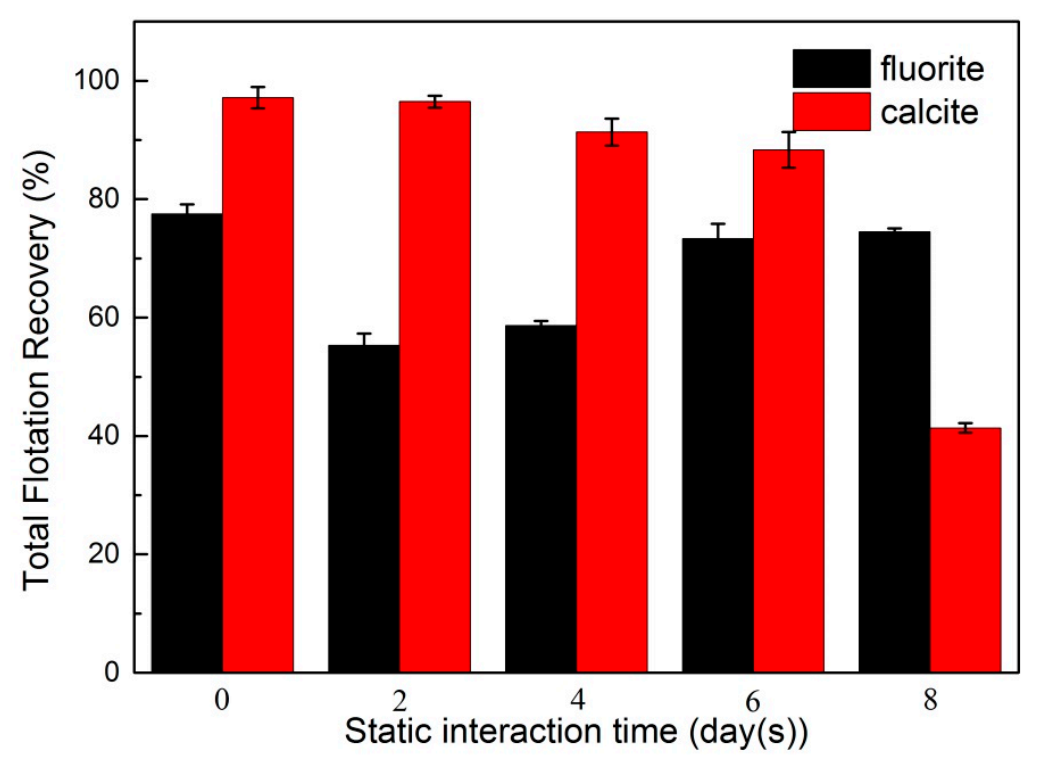

Figure 3. The effect of different static interaction times on the flotation recovery of fluorite and calcite (water glass: $1200 \mathrm{~g} / \mathrm{t}$, the mixture of OA and kerosene: $1200 \mathrm{~g} / \mathrm{t}$ and $\mathrm{pH}: 10$ ).

\subsection{Effect of Static Interaction Time on the Amount of Collector Adsorbed on Fluorite}

The flotation recovery of the single mineral was closely related to the amount of adsorbed collector on the mineral's surface. Consequently, the amount of collector adsorption on the fluorite and calcite surfaces was measured under 0 or 8 days of static interaction. The results are presented in Table 2. It can be seen that the adsorption capacities of the collector on the fluorite and calcite were $0.396 \mathrm{mg} / \mathrm{g}$ and $0.444 \mathrm{mg} / \mathrm{g}$ under 0 days of static interaction, respectively. This result suggested that the collector had a stronger affinity to calcite than to fluorite at the initial time, which resulted in the flotation recovery of calcite being higher than that of fluorite. However, the adsorption capacity of fluorite increased to $0.421 \mathrm{mg} / \mathrm{g}$ and that of calcite decreased to $0.404 \mathrm{mg} / \mathrm{g}$, when the static interaction time increased to 8 days. This result indicated that adsorption and desorption of the collector on the fluorite and calcite surfaces occurred, respectively, after the long-term static interaction between the flotation reagents and minerals. Therefore, the flotation recovery of fluorite treated with reagents for 8 days should be higher than that of calcite, which was consistent with the previous flotation tests results. Thus, it could be concluded that the selective flotation separation of fluorite from calcite mainly depended on the variation of the amount of collector adsorbed on the mineral surfaces. To further elucidate the adsorption mechanisms of the flotation reagents on the mineral surface, the zeta potentials and contact angles of the flotation and calcite were measured.

Table 2. The adsorption capacities of the collector on the mineral for 0 and 8 days of interaction.

\begin{tabular}{cccccccc}
\hline \multirow{2}{*}{ Mineral Sample } & \multirow{2}{*}{$\mathbf{m}(\mathbf{g})$} & \multirow{2}{*}{$\mathbf{V}(\mathrm{L})$} & $\mathbf{C}_{\mathbf{0}}(\mathbf{m g} / \mathrm{L})$ & \multicolumn{2}{c}{ 0 Days } & \multicolumn{2}{c}{$\mathbf{8}$ Days } \\
\cline { 5 - 8 } & & & & $\mathbf{C}_{\mathbf{1}}(\mathbf{m g} / \mathbf{L})$ & $\boldsymbol{\Gamma}(\mathbf{m g} / \mathbf{g})$ & $\mathbf{C}_{\mathbf{2}}(\mathbf{m g} / \mathbf{L})$ & $\Gamma(\mathbf{m g} / \mathbf{g})$ \\
\hline Fluorite & 2 & 0.035 & 32.18 & 9.577 & 0.396 & 8.143 & 0.421 \\
Calcite & 2 & 0.035 & 32.18 & 6.799 & 0.444 & 9.110 & 0.404 \\
\hline
\end{tabular}

\subsection{The Separation of Fluorite and Calcite Facilitated by the Adsorbed Water Glass on Calcite}

The interaction between the flotation reagents and mineral surface could change the surface properties of the minerals, such as the surface electricity and hydrophilicity, thereby influencing the 
flotation behaviors of the minerals. The surface chargeability of mineral samples plays a significant role in minerals' flotation recovery. In this study, zeta potential measurements of fluorite and calcite samples treated with reagents for 0 and 8 days were carried out, and the results are shown in Figure 4. It can be seen that the isoelectric points (IEP) of the raw fluorite and calcite samples were about 9.5 and 10.5 , respectively. The obtained values were also similar to those of the previous study [27,28]. After being treated with flotation reagents for 0 and 8 days, the IEP of the fluorite shifted to about 4.5 and 4 , respectively. Furthermore, the corresponding zeta potentials of the fluorite treated with reagents in the wide $\mathrm{pH}$ ranges were significantly lower than those of the raw fluorite, which was attributed to the adsorption of the flotation reagents, in particular the collector oleic acid. In addition, compared to the fluorite without a long-term static interaction, the samples treated with flotation reagents for 8 days of static interaction exhibited a lower zeta potential. The zeta potentials of the calcite samples showed similar trends with fluorite in the $\mathrm{pH}$ ranges of 7-11. For raw fluorite and samples treated with flotation reagents for 0 and 8 days, the zeta potentials were $-9.44 \mathrm{mV},-15.02 \mathrm{mV}$ and $-27.23 \mathrm{mV}$ under a solution $\mathrm{pH}$ value of 10 , respectively. This could be explained by the larger collector adsorption capacities of samples treated with reagents for 8 days. However, for calcite, the corresponding zeta potentials were $1.12 \mathrm{mV},-1.10 \mathrm{mV}$ and $-13.33 \mathrm{mV}$, respectively, which contradicted the results of the collector adsorption capacities. Therefore, the zeta potentials' variations for calcite may be attributed to other reasons. It was worth noting that the adsorption capacities could be determined according to the variation of the TOC content in the reagents' adsorption capacities. Additionally, the water glass as a depressant was ignored. Nonetheless, the water glass could also be adsorbed on the minerals' surfaces. It has been reported that water glass had a stronger affinity to calcite than to fluorite $[29,30]$. Therefore, it could be speculated that the reduction of the zeta potential of calcite after a long-term static interaction could also be attributed to the adsorbed water glass, which facilitated the separation of fluorite from calcite, and which also agreed with the above results of the flotation tests.
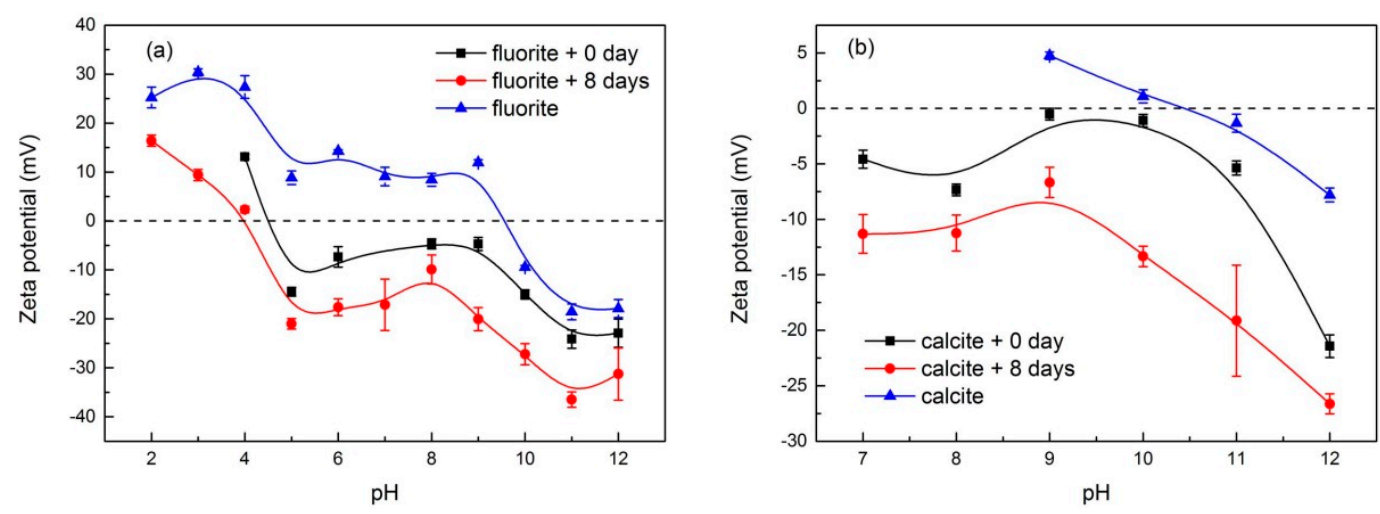

Figure 4. The variation of zeta potential of (a) fluorite and (b) calcite treated with reagents for 0 and 8 days under different $\mathrm{pH}$ values.

\subsection{The Hydrophilicity of Calcite Surface Enhanced after 8 Days of Static Interaction}

To further reveal the differences of the flotation behaviors of minerals treated with reagents for 0 and 8 days, the contact angles of the samples were measured, and the corresponding surface hydrophilicity or hydrophobicity was analyzed. The results are presented in Table 3. The measured contact angles of raw fluorite and calcite were $44.3^{\circ}$ and $45.9^{\circ}$, respectively, indicating that the surfaces of both raw fluorite and calcite were hydrophilic. 
Table 3. The contact angles of minerals treated with reagents for 0 and 8 days.

\begin{tabular}{cccc}
\hline \multirow{2}{*}{ Mineral Samples } & \multicolumn{3}{c}{ Experimental Condition } \\
\cline { 2 - 4 } & No Reagent & Reagents for 0 Days & Reagents for 8 Days \\
\hline Fluorite & $44.3^{\circ} \pm 3.5^{\circ}$ & $134.3^{\circ} \pm 4.2^{\circ}$ & $109.7^{\circ} \pm 3.3^{\circ}$ \\
Calcite & $45.9^{\circ} \pm 3.6^{\circ}$ & $105.0^{\circ} \pm 3.0^{\circ}$ & $52.5^{\circ} \pm 5.0^{\circ}$ \\
\hline
\end{tabular}

After interaction with flotation reagents for 0 days, the contact angles of fluorite and calcite increased to $134.3^{\circ}$ and $105.0^{\circ}$, respectively, suggesting that the minerals' surfaces were hydrophobic. The calcite had smaller contact angles, which was possibly due to the water glass adsorbed on the surface. In addition, after the minerals have been statically incubated with flotation reagents for 8 days, the contact angles of the fluorite and calcite decreased to $109.7^{\circ}$ and $52.5^{\circ}$, respectively. These results indicated that the surface properties of fluorite and calcite changed to different degrees. According to the above contact angle measurements, the surface of the fluorite was still hydrophobic. In contrast to this, the calcite surface showed a high hydrophilicity. These different variations of the two kinds of minerals could be explained by two aspects. On the one hand, the adsorption capacities of collector on calcite were lower than those of fluorite, which significantly decreased the hydrophobicity of calcite. On the other hand, water glass was easily adsorbed on the calcite surface, which on the contrary significantly enhanced the surface hydrophilicity of calcite. Therefore, the differences of the surface properties between fluorite and calcite contributed mainly to the selective separation of fluorite from calcite. Furthermore, in order to further demonstrate the adsorption mode between the flotation reagents and mineral surfaces and reveal the adsorption mechanism of the flotation reagents on the mineral surfaces, FTIR and XPS analyses of minerals treated for 0 and 8 days were carried out.

\subsection{Roles of $\mathrm{Si}-\mathrm{O}$ and $-\mathrm{OH}$ of Water Glass and $\mathrm{C}=\mathrm{O}$ of $\mathrm{OA}$ in the Separation between Fluorite and Calcite}

In order to further demonstrate the adsorption behaviors of the collector on the fluorite and calcite surfaces, the FTIR spectra of reagents and minerals treated with reagents for 0 and 8 days at pH 10 were analyzed (Figure 5). The results in Figure 5a indicated that for kerosene the peaks at $2923.76 \mathrm{~cm}^{-1}$ and $2857.54 \mathrm{~cm}^{-1}$ were assigned to the stretching vibration bonds of $\mathrm{C}-\mathrm{H}$ in the $-\mathrm{CH}_{2}$ and $-\mathrm{CH}_{3}$ functional groups of the alkyl chain, respectively. The peaks at $1459.01 \mathrm{~cm}^{-1}$ and $1376.10 \mathrm{~cm}^{-1}$ were attributed to the symmetric deformation stretching vibration of $-\mathrm{CH}_{3}$. Additionally, the peaks at $670.46 \mathrm{~cm}^{-1}$ and $438.23 \mathrm{~cm}^{-1}$ were the results of the bending vibration of $\mathrm{C}-\mathrm{H}[31,32]$. For OA, the peaks at $2926.56 \mathrm{~cm}^{-1}$ and $2855.32 \mathrm{~cm}^{-1}$ were determined to be the symmetric $-\mathrm{CH}_{2}$ and the asymmetric $-\mathrm{CH}_{2}$ stretching vibration, respectively. The intense stretching vibration absorption peak of the $\mathrm{C}=\mathrm{O}$ group was determined near $1710 \mathrm{~cm}^{-1}$. The bond at $1286.24 \mathrm{~cm}^{-1}$ was derived from the existence of the $\mathrm{C}-\mathrm{O}$ stretch, and the bonds at $1459.91 \mathrm{~cm}^{-1}$ and $938.40 \mathrm{~cm}^{-1}$ exhibited the presence of the $\mathrm{O}-\mathrm{H}$ in-plane and out-of-plane, respectively [33-35]. Furthermore, for water glass, a broad absorption peak at $3454.19 \mathrm{~cm}^{-1}$ and a small absorption peak at $1641.02 \mathrm{~cm}^{-1}$ could be due to the stretching vibration and bending vibration of the $-\mathrm{OH}$ groups. The asymmetrical stretching vibration and symmetrical stretching vibration of the $\mathrm{Si}-\mathrm{O}$ bonds appeared at $1142.99 \mathrm{~cm}^{-1}$ and $887.85 \mathrm{~cm}^{-1}$, respectively $[36,37]$.

In the spectrum of bare calcite (Figure $5 b$ ), the adsorption bond at $1442.73 \mathrm{~cm}^{-1}$ was due to the stretching vibration of $\mathrm{CO}_{3}{ }^{2-}$, and the absorption bonds at $876.85 \mathrm{~cm}^{-1}$ and $712.70 \mathrm{~cm}^{-1}$ were the results of the deformation vibration of $\mathrm{CO}_{3}{ }^{2-}$ [38]. After a treatment with reagents for 0 days, new adsorption bonds emerged at $2982.62 \mathrm{~cm}^{-1}, 1798.53 \mathrm{~cm}^{-1}, 1426.93 \mathrm{~cm}^{-1}$ and $2349.68 \mathrm{~cm}^{-1}$. The first three bonds indicated the adsorption of $\mathrm{OA}$ on the calcite surface, and the shift of the stretching vibration peak of carboxyl of OA from $1710.53 \mathrm{~cm}^{-1}$ to $1798.53 \mathrm{~cm}^{-1}$ demonstrated that the interaction between OA and the calcite surface was essentially chemisorption. The adsorption bond appeared at $2349.68 \mathrm{~cm}^{-1}$, which confirmed that kerosene was adsorbed on the calcite surface. After the treatment with reagents for 8 days, the results were similar to those of calcite treated with reagents for 0 days. However, 
a shift of the adsorption peaks from $1703.19 \mathrm{~cm}^{-1}$ to $1698.20 \mathrm{~cm}^{-1}$ could be observed, indicating that water glass was adsorbed onto calcite. Moreover, the difference of calcite treated for 8 days was not significant at $2983.47 \mathrm{~cm}^{-1}$ as compared to raw calcite, indicating that OA desorption occurred on the calcite surface after the calcite was treated with reagents for 8 days.
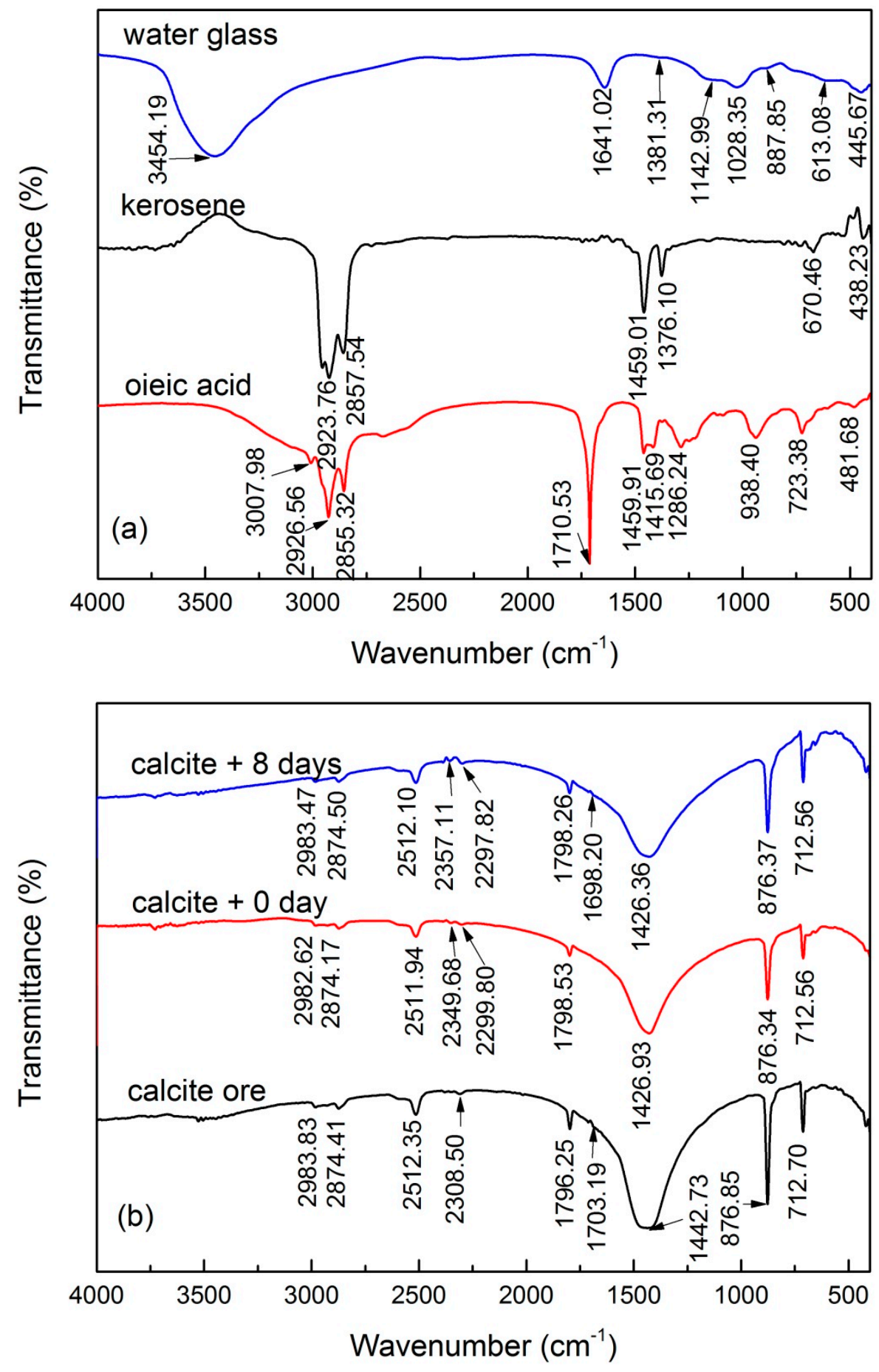

Figure 5. Cont. 


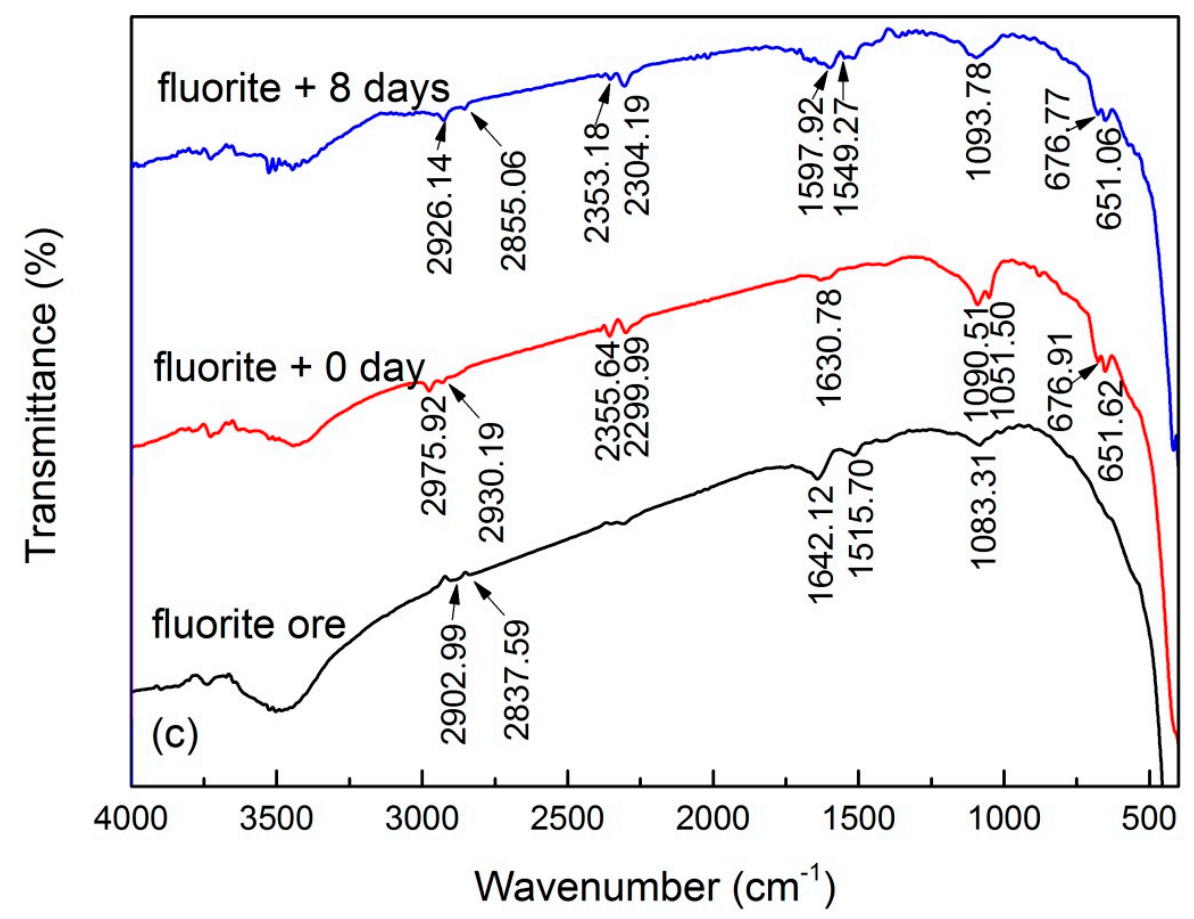

Figure 5. The FTIR spectra of (a) reagents, (b) calcite and (c) fluorite treated with reagents for 0 and 8 days.

Figure 5 c shows the FTIR spectra of fluorite treated with reagents for 0 and 8 days. For the sample treated with reagents for 0 days, new adsorption bonds emerged at $2930.19 \mathrm{~cm}^{-1}$ and $2975.92 \mathrm{~cm}^{-1}$, which were assigned to $-\mathrm{CH}_{3}$ and $-\mathrm{CH}_{2}$ stretching vibrations [39]. The bonds which appeared at $2299.99 \mathrm{~cm}^{-1}, 2355.64 \mathrm{~cm}^{-1}, 676.91 \mathrm{~cm}^{-1}$ and $651.62 \mathrm{~cm}^{-1}$ suggested that kerosene was absorbed on the fluorite surface. The bonds at $1090.51 \mathrm{~cm}^{-1}$ and $1051.50 \mathrm{~cm}^{-1}$ were derived from the adsorption of water glass on fluorite. Furthermore, the weak adsorption peak near $1630 \mathrm{~cm}^{-1}$ was the result of a $\mathrm{C}=\mathrm{O}$ stretching vibration, indicating that a small amount of OA on the fluorite surface underwent chemisorption. Fluorite treated with reagents for 8 days showed negligible differences as compared to those of fluorite treated for 0 days. The intense peaks which emerged at $1549.27 \mathrm{~cm}^{-1}$ and $1597.92 \mathrm{~cm}^{-1}$ demonstrated a strong interaction between $\mathrm{OA}$ and the fluorite surface, and the adsorption peak of water glass on fluorite treated for 8 days was weaker at $1093.78 \mathrm{~cm}^{-1}$ than that of fluorite treated for 0 days, indicating that the adsorption capacity of water glass on the fluorite surface decreased.

\subsection{Effect of Static Interaction Time on the Amount of OA in Collector Adsorbed on Calcite}

To further elucidate the adsorption mechanism of flotation reagents on the calcite surface, the XPS was then conducted. As expected, C, Ca and $\mathrm{O}$ were the major constituents, and no adventitious contaminants or impurities were detected (Figure 6). The C1s spectra of calcite ore and calcite treated with reagents for 0 and 8 days were summarized in Figure 7 . It can be seen that the C1s spectrum of the original calcite has two peaks at 284.91 and $289.45 \mathrm{eV}$. After the reagents' treatment for 0 days, the C1s spectrum could be well deconvoluted, with three components. The major peak at $284.79 \mathrm{eV}$ was considered as the reference C1s, and other two peaks at 286.10 and $289.54 \mathrm{eV}$ were assigned to $\mathrm{C}-\mathrm{O}$ and $\mathrm{C}=\mathrm{O}$ in $\mathrm{OA}$ molecules. The $\mathrm{C} 1 \mathrm{~s}$ spectrum of calcite treated with reagents for 8 days could also be fitted with three components and resulted in similar conclusions at the 286.09 and $289.52 \mathrm{eV}$ peaks, providing further evidence of the chemical adsorption interaction of the collector on the calcite surface. Furthermore, as compared with calcite for 0 days, the areas of the $\mathrm{C}-\mathrm{O}$ and $\mathrm{C}=\mathrm{O}$ functional groups of calcite for 8 days decreased by $0.34 \%$ (from $5.00 \%$ to $4.66 \%$ ) and $1.93 \%$ (from $42.52 \%$ to $40.59 \%$ ), respectively. The results demonstrated that the adsorption quantities of collector on calcite 
for 8 days declined more than those of calcite for 0 days, which was consistent with the results of the flotation tests.

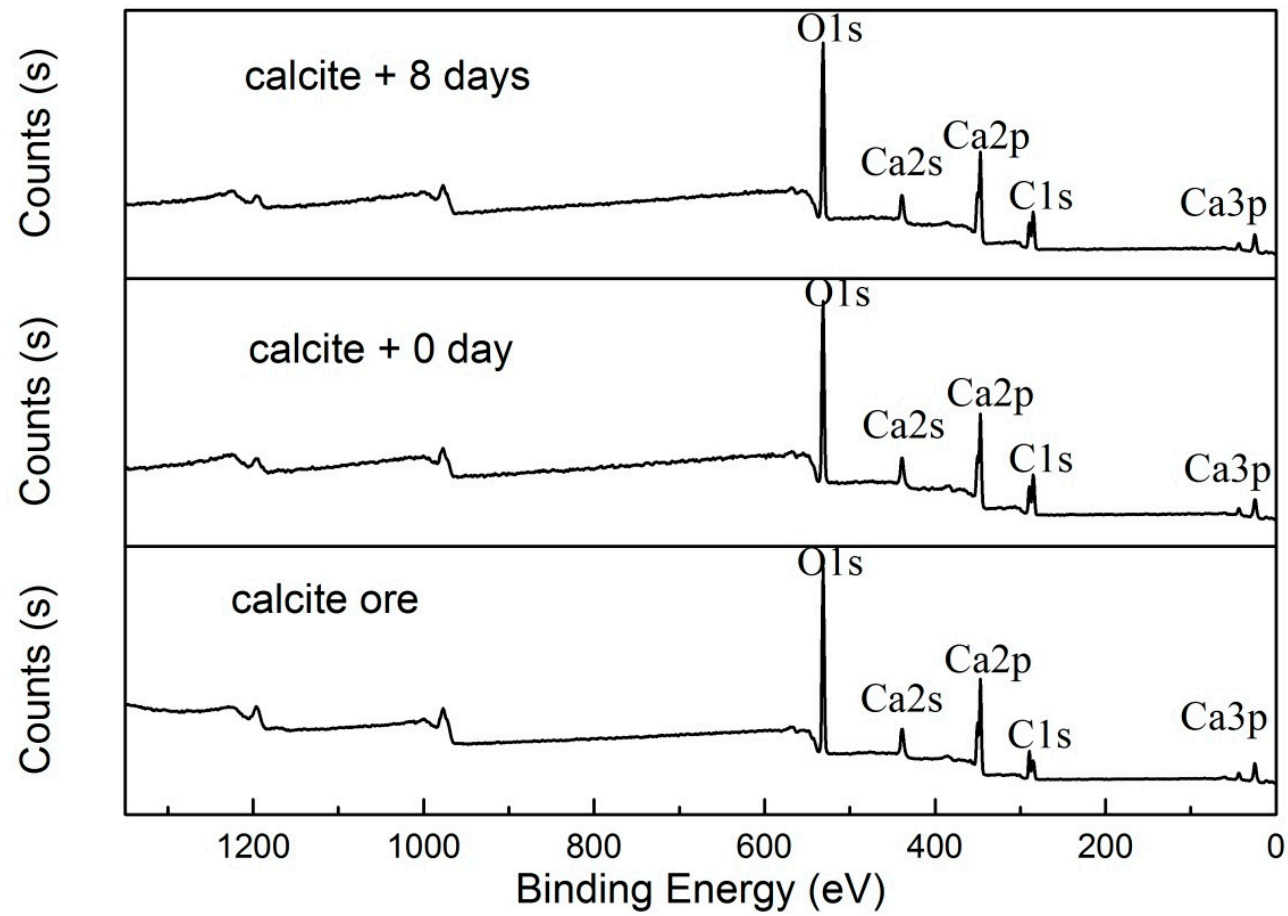

Figure 6. The XPS spectra of calcite ore and calcite treated for 0 and 8 days.

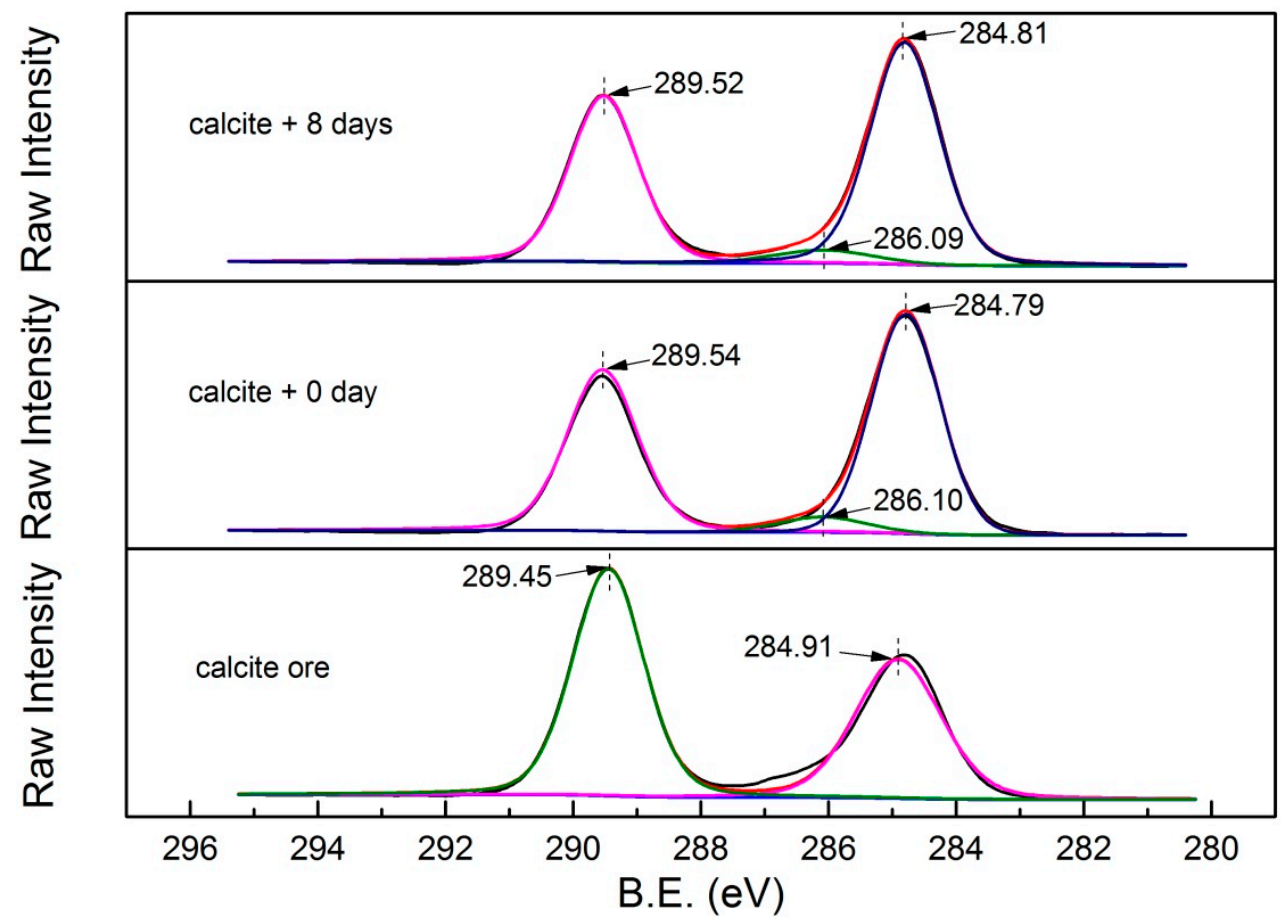

Figure 7. The XPS C1s spectra of calcite treated with collector for 0 and 8 days.

Figure 8 displays the Ca2p spectra of calcite ore and calcite treated with flotation reagents for 0 and 8 days. It had been documented that the Ca2p spectrum of calcite ore could be well fitted with two peaks, with binding energies of $346.95 \mathrm{eV}$ for the $\mathrm{Ca}_{3 / 2}$ level and $350.51 \mathrm{eV}$ for the $\mathrm{Ca}_{1 / 2}$ level. The calcium ion peaks of calcite conditioned with collector for 0 or 8 days shifted to higher binding energies at $347.12 \mathrm{eV}$ and $350.68 \mathrm{eV}$, indicating that the electron density around the calcium 
ion changed. Meanwhile, the carboxyl groups (COO-) of the OA molecules were conjugated with the calcium ions exposed on the calcite surface [40]. Therefore, the conclusions provided further evidence for the chemical interaction between the OA molecules and calcite during the adsorption process.

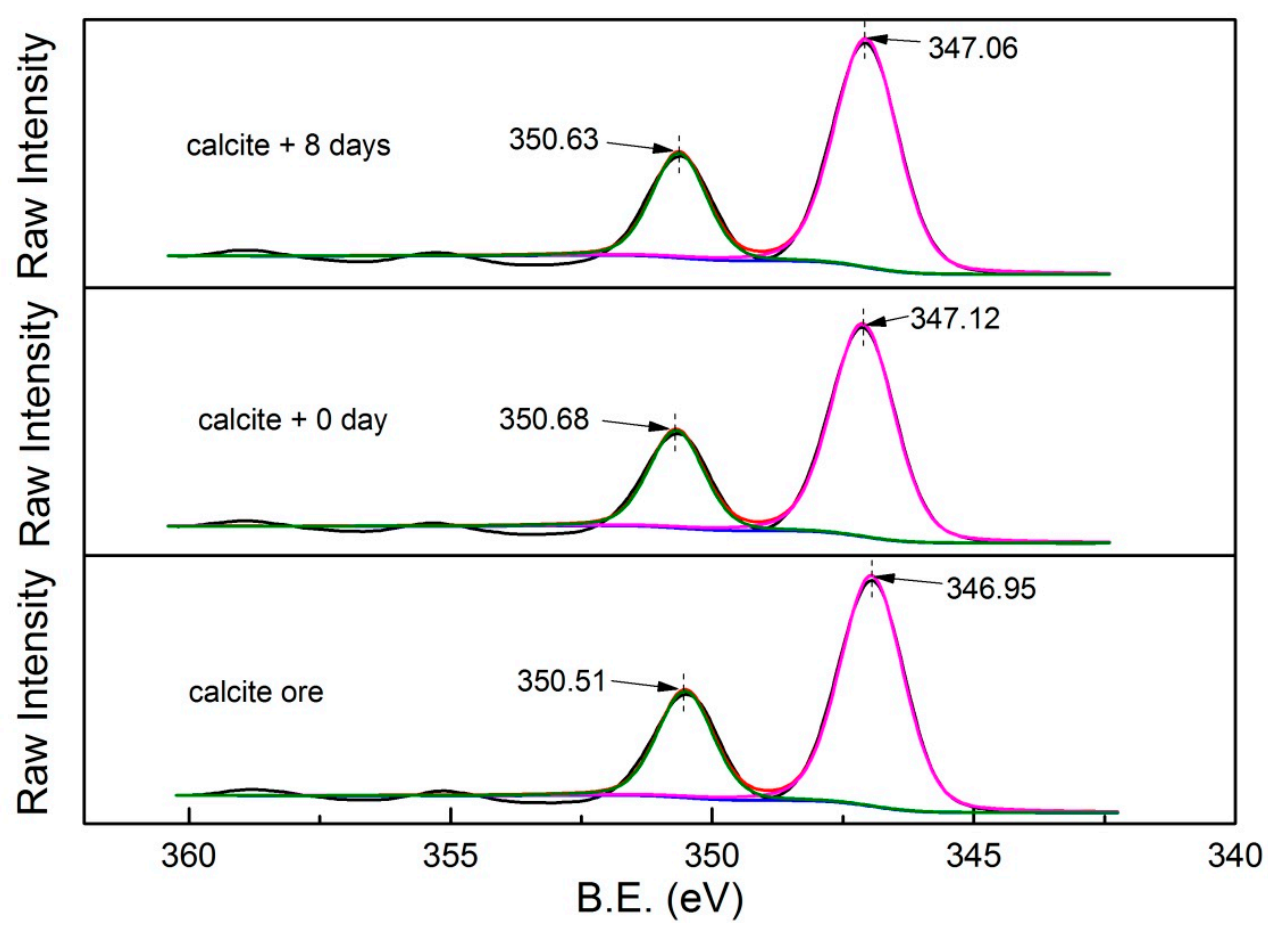

Figure 8. The XPS Ca2p spectra of calcite treated with collector for 0 and 8 days.

As shown in Figure 9, it is easy to notice that the O1s spectrum of raw calcite has only one peak at $531.35 \mathrm{eV}$, corresponding to negative oxygen ions in carbonate. This result is similar to the previous report [9]. After flotation reagent treatments for 0 or 8 days, the O1s spectrum of calcite exhibited a new peak at $532.04 \mathrm{eV}$ or $531.96 \mathrm{eV}$, which suggested that the flotation reagents were chemisorbed on the calcite surface [38]. Moreover, the peak area of the O1s spectrum of calcite treated for 8 days at the binding energy of $531.96 \mathrm{eV}$ decreased by $0.32 \%$ (from $31.74 \%$ to $31.42 \%$ ), providing further evidence for the reduction of the recovery rate of calcite treated for 8 days as compared to that of calcite treated for 0 days. 


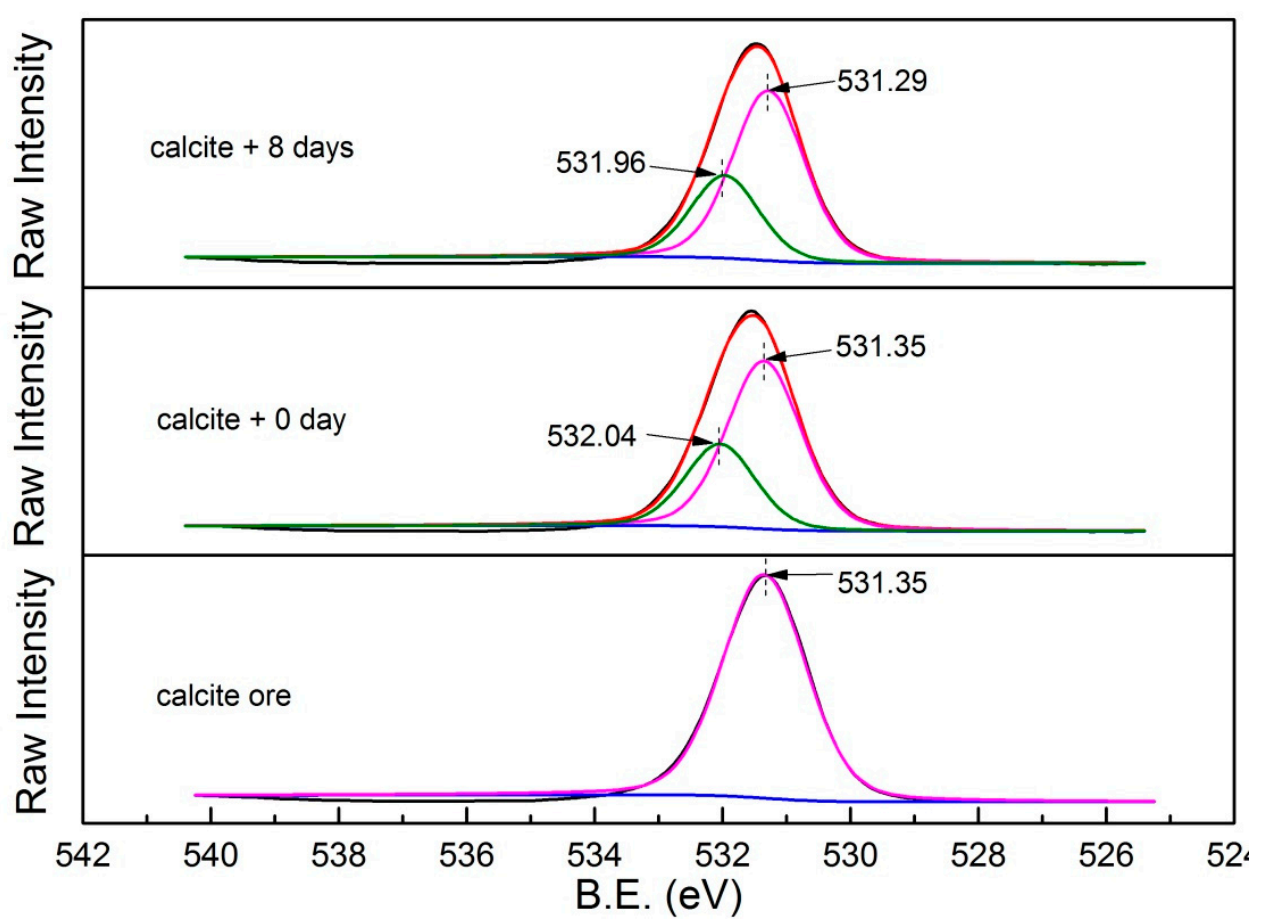

Figure 9. The XPS O1s spectra of calcite treated with collector for 0 and 8 days.

\subsection{Effect of Long-Term Interaction on the Flotation Separation between Fluorite and Calcite in Tailings}

To verify the applicability of the above results, batch flotation tests of tailings from Jiangxi were then conducted. The flotation results are summarized in Table 4 and Figure 10. The results indicated that the grade and recovery rate of fluorite increased dramatically from $87.18 \%$ and $40.99 \%$ to $93.00 \%$ and $46.01 \%$, respectively, when the static interaction between the flotation reagents and tailings was extended from 0 days to 8 days. These results were in accordance with the single mineral tests, indicating that increasing the static interaction time between the flotation reagents and minerals was beneficial to the selective separation of fluorite from calcite.

Table 4. The flotation concentrate results of tailings treated for 0 and 8 days.

\begin{tabular}{ccccc}
\hline \multirow{2}{*}{ Concentrates } & \multicolumn{2}{c}{ 0 Day } & \multicolumn{2}{c}{ 8 Days } \\
\cline { 2 - 5 } & Grade (\%) & Recovery (\%) & Grade (\%) & Recovery (\%) \\
\hline Fluorite & 87.18 & 40.99 & 93.00 & 46.01 \\
Calcite & 48.28 & 44.36 & 44.39 & 42.92 \\
\hline
\end{tabular}




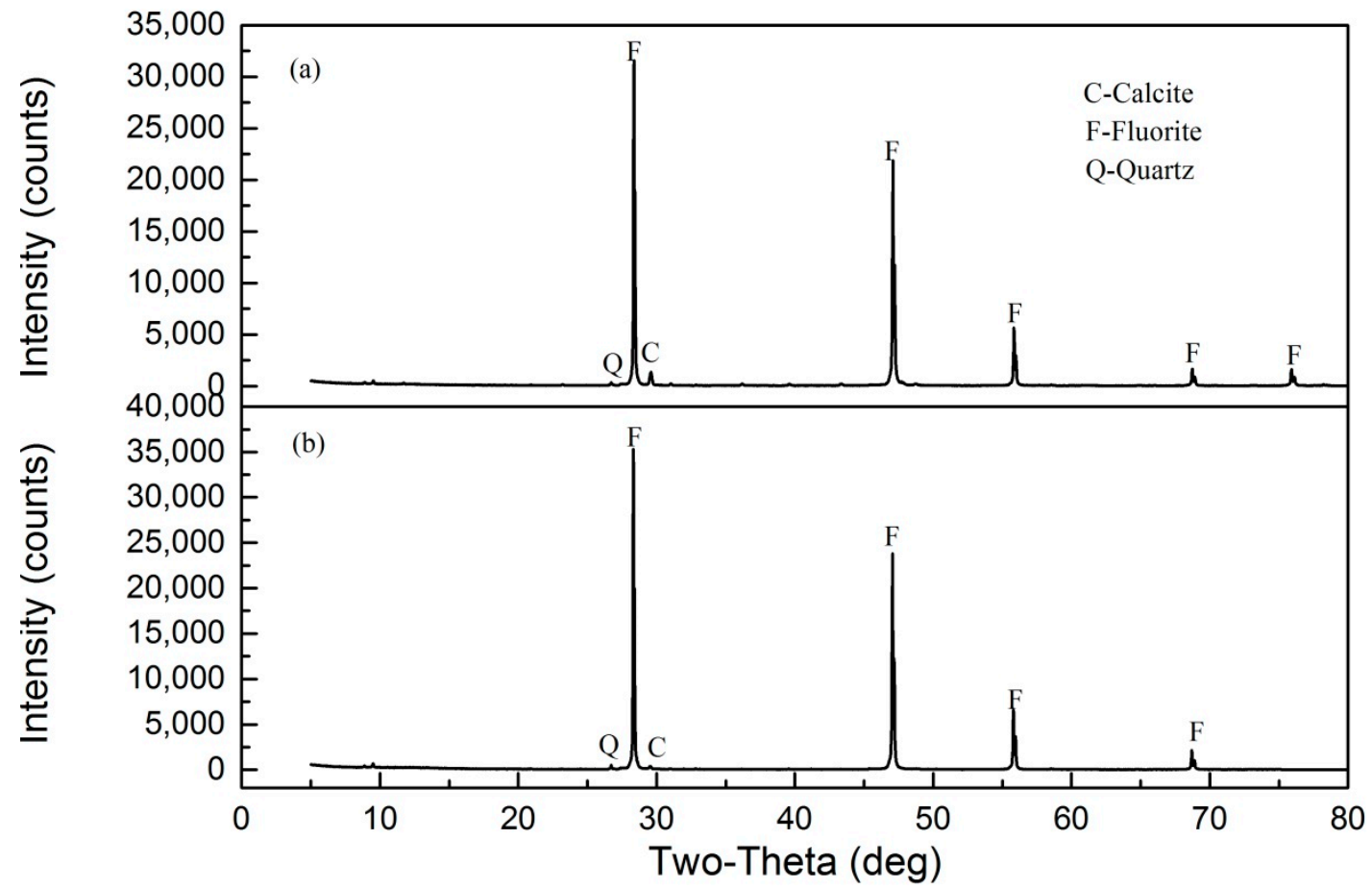

Figure 10. The XRD spectra of the concentrates of tailings treated for (a) 0 day and (b) 8 days.

\section{Conclusions}

Previous studies have shown that the interaction between flotation reagents and mineral surfaces could achieve equilibrium within minutes or tens of minutes, but a long-term static interaction has not been reported. The results in this work indicated that a long-term static interaction was beneficial for the effective separation of fluorite from calcite by flotation. When the static interaction between flotation reagents and minerals was extended to 8 days, the adsorption capacity of the collector on the fluorite surface was higher than that of calcite. After 8 days of static interaction, the adsorption of the flotation reagents on the mineral surfaces could change the surface properties of fluorite and calcite, such as the hydrophobicity and floatability, making the fluorite more hydrophobic and calcite more hydrophilic. FTIR and XPS analyses further demonstrated that the chemical adsorption of the collector occurred on the two kinds of mineral surfaces. Furthermore, the amount of carboxyl groups from OA molecules adsorbed on calcite treated for 8 days was less than that for calcite treated for 0 days. In addition, the flotation results of tailings from Jiangxi verified that the long-term static interaction between the flotation reagents and minerals could change the flotation behaviors of mineral surfaces and promote the separation between fluorite and calcite in tailings, increasing the grade and recovery of fluorite. It can be concluded from this study that the static interaction time between flotation reagents and minerals plays an important role in the flotation process, which also provides significant theoretical clues for environment-friendly ways to stack flotation tailings.

Author Contributions: Conceptualization, H.Z. and Z.H.; methodology, L.H. (Leiming Huang) and Q.Z.; formal analysis, L.H. (Leiming Huang); investigation, L.H. (Leiming Huang); resources, Z.H. and H.Z.; data curation, L.H. (Leiming Huang); writing—original draft preparation, L.H. (Leiming Huang); writing—review and editing, L.H. (Liang Hu), Z.H. and Q.Z.; supervision Z.H. and H.Z.; project administration, Z.H. and H.Z.; funding acquisition, Y.H., H.Z. and Z.H.

Funding: The authors gratefully acknowledge the financial support by National Key Research \& Development Plan of China (No. 2018YFC1900405).

Conflicts of Interest: The authors declare no conflict of interest. The funders had no role in the design of the study; in the collection, analyses, or interpretation of data; in the writing of the manuscript, or in the decision to publish the results. 


\section{References}

1. Jiang, W.; Gao, Z.; Sun, W.; Gao, J.; Hu, Y. A Density Functional Theory Study on the Effect of Lattice Impurities on the Electronic Structures and Reactivity of Fluorite. Minerals 2017, 7, 160. [CrossRef]

2. Liu, S.; Lu, X.; Wei, S. Study on Flotation Process of Low Quality Fluorite ore. Adv. Mater. Res. 2013, 753-755, 36-39. [CrossRef]

3. Li, Y.J.; Sun, F.Y.; Zhou, Y.; Zeng, L. The Improvement Effect of Dispersant in Fluorite Flotation: Determination by the Analysis of XRD and FESEM-EDX. J. Spectrosc. 2015, 2015, 1-5. [CrossRef]

4. Yang, J.; Liu, Q.; Guo, Y.; Xiao, H.; Jiang, M. Research of the Low Grade Fluorite Flotation Orthogonal Test. Adv. Mater. Res. 2013, 734-737, 1068-1072. [CrossRef]

5. Zheng, R.; Ren, Z.; Gao, H.; Chen, Z.; Qian, Y.; Li, Y. Effects of crystal chemistry on sodium oleate adsorption on fluorite surface investigated by molecular dynamics simulation. Miner. Eng. 2018, 124, 77-85. [CrossRef]

6. Gao, Z.; Gao, Y.; Zhu, Y.; Hu, Y.; Sun, W. Selective Flotation of Calcite from Fluorite: A Novel Reagent Schedule. Minerals 2016, 6, 114. [CrossRef]

7. Yarar, B.; Richter, R.B. Flotation. In Ullmann's Encyclopedia of Industrial Chemistry, 7th ed.; Elvers, B., Ed.; Wiley-VCH Verlag GmbH \& Co. KGaA: Weinheim, Germany, 2016. [CrossRef]

8. Fa, K.; Jiang, T.; Nalaskowski, J.; Miller, J.D. Interaction Forces between a Calcium Dioleate Sphere and Calcite/Fluorite Surfaces and Their Significance in Flotation. Langmuir 2003, 19, 10523-10530. [CrossRef]

9. Zhang, C.; Wei, S.; Hu, Y.; Tang, H.; Gao, J.; Yin, Z.; Guan, Q. Selective adsorption of tannic acid on calcite and implications for separation of fluorite minerals. J. Colloid Interface Sci. 2018, 512, 55-63. [CrossRef] [PubMed]

10. Hanna, H.S.; Somasundaran, P. Flotation of Salt-Type Minerals, 8th ed.; Fuerstenau, M.C., Ed.; American Institute of Mining, Metallurgical and Petroleum Engineers: New York, NY, USA, 1976; Flotation-A.M. Gaudin Memorial Volume; pp. 197-272.

11. Finkelstein, N.P. Review of interactions in flotation of sparingly soluble calcium minerals with anionic collectors. Trans. Inst. Min. Metall. 1989, 98, 157-177.

12. Somasundaran, P.; Healy, T.W.; Fuerstenau, D.W. Surfactant adsorption at the solid-liquid interface-dependence of mechanism on chain length. J. Phys. Chem. 1964, 68, 3562-3566. [CrossRef]

13. Chennakesavulu, K.; Raju, G.B.; Prabhakar, S.; Nair, C.M.; Murthy, K.V.G.K. Adsorption of oleate on fluorite surface as revealed by atomic force microscopy. Int. J. Miner. Process. 2009, 90, 101-104. [CrossRef]

14. Zheng, R.; Ren, Z.; Gao, H.; Qian, Y. Flotation Behavior of Different Colored Fluorites Using Sodium Oleate as a Collector. Minerals 2017, 7, 159. [CrossRef]

15. Liu, Q.; Zhang, Y.; Laskowski, J.S. The adsorption of polysaccharides onto mineral surfaces: An acid/base interaction. Int. J. Miner. Process. 2000, 60, 229-245. [CrossRef]

16. Ren, Z.; Yu, F.; Gao, H.; Chen, Z.; Peng, Y.; Liu, L. Selective Separation of Fluorite, Barite and Calcite with Valonea Extract and Sodium Fluosilicate as Depressants. Minerals 2017, 7, 24. [CrossRef]

17. Fuerstenau, D.W.; Bunge, R.C. The complex behavior of fatty acids in fluorite flotation. XXXIII Miner. Process. Congress 2006, 1, 510-515.

18. Helbig, C.; Baldauf, H.; Mahnke, J.; Stöckelhuber, K.W.; Schulze, H.J. Investigation of Langmuir monofilms and flotation experiments with anionic/cationic collector mixtures. Int. J. Miner. Process 1998, 53, 135-144. [CrossRef]

19. Helbig, C.; Baldauf, H.; Lange, T.; Newmann, R.; Pollex, R.; Weber, E. New binary collectors with increased flotation efficiency. Tenside Surfact. Deterg. 1999, 36, 58-62.

20. Zhang, G.; Gao, Y.; Chen, W.; Liu, D. The Role of Water Glass in the Flotation Separation of Fine Fluorite from Fine Quartz. Minerals 2017, 7, 157. [CrossRef]

21. Pugh, R.; Stenius, P. Solution chemistry studies and flotation behaviour of apatite, calcite and fluorite minerals with sodium oleate collector. Int. J. Miner. Process 1985, 15, 193-218. [CrossRef]

22. Song, Y.; Wang, J.; Jin, H.; Hu, X.; Qi, M. A study on Molecular Mechanics Analysis Flotation Collector in the process management Fluorite Tailing Mining. Appl. Mech. Mater. 2014, 577, 1223-1227. [CrossRef]

23. Alghunaim, A.; Kirdponpattara, S.; Newby, B.-M.Z. Techniques for determining contact angle and wettability of powders. Powder Technol. 2016, 287, 201-215. [CrossRef]

24. Dong, X.; Zong, Q.; He, J. Anisotropic surface properties and wettability of disperse dye single crystal. Dyes Pigments 2013, 9, 636-641. [CrossRef] 
25. Tang, H.; Zhao, L.; Sun, W.; Hu, Y.; Han, H. Surface characteristics and wettability enhancement of respirable sintering dust by nonionic surfactant. Colloids Surf. A 2016, 509, 323-333. [CrossRef]

26. Marinakis, K.I.; Shergold, H.L. The mechanism of fatty acid adsorption in the presence of fluorite, calcite and barite. Int. J. Miner. Process 1985, 14, 161-176. [CrossRef]

27. Yao, W.; Li, M.; Zhang, M.; Cui, R.; Jiang, H.; Li, Y.; Zhou, S. Effects of grinding media on flotation performance of calcite. Miner. Eng. 2019, 132, 92-94. [CrossRef]

28. Fuerstenau, D.W.; Herrera-Urbina, R. The surface chemistry of bastnaesite, barite and calcite in aqueous carbonate solutions. Colloids Surf. 1992, 68, 95-102. [CrossRef]

29. Gao, Z.; Bai, D.; Sun, W.; Cao, X.; Hu, Y. Selective flotation of scheelite from calcite and fluorite using a collector mixture. Miner. Eng. 2015, 72, 23-26. [CrossRef]

30. Marinakis, K.I.; Shergold, H.L. Influence of sodium silicate addition on the adsorption of oleic acid by fluorite, calcite and barite. Int. J. Miner. Process 1985, 14, 177-193. [CrossRef]

31. Gao, J.; Hu, Y.; Sun, W.; Liu, R.; Gao, Z.; Han, H.; Lyu, F.; Jiang, W. Enhanced separation of fluorite from calcite in acidic condition. Miner. Eng. 2019, 133, 103-105. [CrossRef]

32. Dadson, J.; Pandam, S.; Asiedu, N. Modeling the characteristics and quantification of adulterants in gasoline using FTIR spectroscopy and chemometric calibrations. Cogent. Chem. 2018, 4, 1-22. [CrossRef]

33. He, T.; Li, H.; Jin, J.; Peng, Y.; Wang, Y.; Wan, H. Improving fine molybdenite flotation using a combination of aliphatic hydrocarbon oil and polycyclic aromatic hydrocarbon. Results Phys. 2019, 12, 1050-1055. [CrossRef]

34. Pinilla, C.M.B.; Thys, R.C.S.; Brandelli, A. Antifungal properties of phosphatidylcholine-oleic acid liposomes encapsulating garlic against environmental fungal in wheat bread. Int. J. Food Microbiol. 2019, 293, 72-78. [CrossRef] [PubMed]

35. Gholoobi, A.; Abnous, K.; Ramezani, M.; Shandiz, F.H.; Darroudi, M.; Ghayour-Mobarhan, M.; Meshkat, Z. Synthesis of $\gamma-\mathrm{Fe}_{2} \mathrm{O}_{3}$ Nanoparticles Capped with Oleic Acid and their Magnetic Characterization. Iran. J. Sci. Technol. A 2017, 42, 1889-1893. [CrossRef]

36. Zhang, L.; He, R.; Gu, H. Oleic acid coating on the monodisperse magnetite nanoparticles. Appl. Surf. Sci. 2006, 253, 2611-2617. [CrossRef]

37. Luo, Y.; Zheng, S.; Ma, S.; Liu, C.; Ding, J.; Wang, X. Novel two-step process for synthesising $\beta$-SiC whiskers from coal fly ash and water glass. Ceram. Int. 2018, 44, 10585-10595. [CrossRef]

38. Chen, W.; Feng, Q.; Zhang, G.; Yang, Q. Investigations on flotation separation of scheelite from calcite by using a novel depressant: Sodium phytate. Miner. Eng. 2018, 126, 116-122. [CrossRef]

39. Zhu, H.; Qin, W.; Chen, C.; Chai, L.; Jiao, F.; Jia, W. Flotation separation of fluorite from calcite using polyaspartate as depressant. Miner. Eng. 2018, 120, 80-86. [CrossRef]

40. Wei, Z.; Hu, Y.; Han, H.; Sun, W.; Wang, R.; Wang, J. Selective flotation of scheelite from calcite using $\mathrm{Al}-\mathrm{Na}_{2} \mathrm{SiO}_{3}$ polymer as depressant and Pb-BHA complexes as collector. Miner. Eng. 2018, 120, $29-34$. [CrossRef]

(C) 2019 by the authors. Licensee MDPI, Basel, Switzerland. This article is an open access article distributed under the terms and conditions of the Creative Commons Attribution (CC BY) license (http://creativecommons.org/licenses/by/4.0/). 